\title{
Hallucinogens/psychedelics resurrected as new tools in psychiatric therapy
}

\author{
Rafael G. dos Santos, ${ }^{1,2,3}$ (DD José C. Bouso, ${ }^{3}$ (D) Jaime E. Hallak ${ }^{1,2}$ (DD \\ ${ }^{1}$ Departamento de Neurociências e Ciências do Comportamento, Faculdade de Medicina de Ribeirão Preto, Universidade de São Paulo, \\ Ribeirão Preto, SP, Brazil. ${ }^{2}$ Instituto Nacional de Ciência e Tecnologia Translacional em Medicina (INCT-TM), CNPq, Ribeirão Preto, SP, \\ Brasil. ${ }^{3}$ Fundación ICEERS, Barcelona, Spain.
}

Hallucinogens (from the Latin alucinari, "to wander in mind") or psychedelics (from the Greek words psyche [mind] and delos [visible], thus "to see/manifest the mind") are a group of substances that induce profound changes in thinking patterns, sensory perception, emotion and cognition without clouding the mind. The main examples of this group of drugs are lysergic acid diethylamide (LSD), mescaline, psilocybin, and dimethyltryptamine (DMT). These chemicals are also called serotonergic or classic hallucinogens/psychedelics and share a central pharmacological mechanism: $5-\mathrm{HT}_{2 \mathrm{~A}}$ receptor agonism. ${ }^{1}$

These drugs, especially LSD and psilocybin, where intensively investigated in psychiatry from the late 1950s to the early 1970 s and were considered promising treatments for mood and anxiety disorders and drug dependence. However, the recreational use of these compounds by the counterculture, followed by new legislation for drug trials, restricted this line of research in the early 1970s. Now, decades later, experimental and clinical research on these drugs has been re-established by research groups in Switzerland (LSD and psilocybin), Brazil (ayahuasca), the United States (psilocybin), and the United Kingdom (LSD and psilocybin), finding preliminary but promising results. ${ }^{2}$

Randomized controlled trials (RCTs) have found positive results for psilocybin in obsessive-compulsive disorder and for both psilocybin and LSD in anxiety and depression in end-stage cancer., ${ }^{1,2}$ Our group in the Faculdade de Medicina, Universidade de São Paulo, in Ribeirão Preto, in collaboration with the Universidade Federal do Rio Grande do Norte, was the first to report that a single dose of ayahuasca produced significant reductions in depressive and anxiety symptoms in 29 patients with treatment-resistant major depression disorder. ${ }^{3}$ For seven days after administration of the drug, greater symptom reduction was observed in the ayahuasca group than the control group. ${ }^{3}$ This result is important because traditional antidepressants often need weeks of daily intake to achieve therapeutic effects and

Correspondence: Rafael Guimarães dos Santos, Departamento de Neurociências e Ciências do Comportamento, Faculdade de Medicina de Ribeirão Preto, Universidade de São Paulo, Hospital das Clínicas, Terceiro Andar, Av. Bandeirantes, 3900, Ribeirão Preto, SP, Brazil.

E-mail: banisteria@gmail.com

Submitted Apr 15 2020, accepted Apr 16 2020, Epub Jun 012020. often produce significant adverse effects. RCTs with hallucinogens/psychedelics have found both acute and prolonged therapeutic effects after a single dose or a few doses, and the drugs were well tolerated. ${ }^{1-3}$

Moreover, observational studies of ritual ayahuasca users conducted by the ICEERS Foundation in Spain, in collaboration with our group, reported that continuous ayahuasca use is apparently safe and has therapeutic effects. ${ }^{4,5}$ The results of a self-administered questionnaire showed that ritual ayahuasca users had high scores for psychosocial adjustment, stress coping strategies and indicators of perceived social support (e.g., how many family members and close friends they had, whether an acquaintance would accompany them to the doctor if needed, whether there are people who express affection for them, and having someone to share joy or sadness and private fears or concerns with). ${ }^{4}$ Furthermore, compared with ayahuasca-naïve controls, ayahuasca use was associated with a significant reduction in depression, a significant improvement in quality of life, and reduced use of prescription medications. ${ }^{5}$ Taken together, evidence from preliminary RCTs with LSD, psilocybin and ayahuasca and evidence from naturalist studies of ritual ayahuasca use suggest that these compounds have therapeutic potential for difficult-to-treat mental health problems and enhance community bonds and social support, which can be a protective factor in mental health.

The main risks of these drugs include acute anxiety and psychotic-like symptoms, but RCTs have shown that these effects can be managed with non-pharmacological approaches and are reduced if patients are rigorously selected and proper monitored. Indeed, no evidence of prolonged or serious adverse effects was found in any of the previously mentioned trials, ${ }^{1-3}$ and observational studies of ritual ayahuasca use support those results. ${ }^{4,5}$

Experimental and clinical research with ayahuasca can be conducted in Brazil without the regulatory problems faced by investigations of LSD and psilocybin, which are Schedule 1 controlled substances. Ritual use of

How to cite this article: dos Santos RG, Bouso JC, Hallak JE. Hallucinogens/psychedelics resurrected as new tools in psychiatric therapy. Braz J Psychiatry. 2021;43:119-120. http://dx.doi.org/ 10.1590/1516-4446-2020-1035 
ayahuasca by religious organizations such as the Santo Daime, Barquinha and União do Vegetal has been allowed in Brazil since the 1980s, and ayahuasca has been used ritually and therapeutically by several indigenous groups in the Brazilian Amazon for generations. This cultural context places ayahuasca in a more acceptable position than LSD or psilocybin, which are usually classified as recreational drugs. Moreover, the plants used to prepare ayahuasca (the liana Banisteriopsis caapi and the bush Psychotria viridis) are endemic to Brazil and other Amazonian countries such as Peru and Colombia. Therefore, these favorable cultural, biological and clinical aspects should stimulate further investigation of this compound.

These results are especially relevant during the delicate juncture produced by the COVID-19 pandemic. People worldwide are dealing with different levels of stress, anxiety, depression and social isolation, which ranges from mild to total confinement. The psychological impact of this pandemic is beginning to emerge in both health professionals and the general public, with signs of increased mental health problems. The preliminary but significant evidence of improvement in mood and anxiety disorders reported in RCTs, as well as the improvement in psychosocial adjustment, coping strategies and perceived social support reported in observational studies make us optimistic about the potential beneficial effects of these drugs, when used in carefully controlled contexts, whether clinical or ritual.

Therefore, further clinical and naturalistic studies in larger samples are necessary to replicate these results and evaluate the long-term efficacy and safety of these compounds. Although these compounds are not "magic bullets" or "miracle drugs," they indicate the possibility of a brave new world in psychiatric treatment, and we are cautiously optimistic about their potential.

\section{Acknowledgements}

RGS is a fellow of the Programa Nacional de PósDoutorado, Coordenação de Aperfeiçoamento de Pessoal de Nível Superior (PNPD/CAPES) and a member of the advisory board of Fundación ICEERS, a non-profit organization that promotes the scientific research on plant hallucinogens, such as ayahuasca and ibogaine. JCB is the Scientific Director of Fundación ICEERS. JEH has a 1A productivity fellowship from the Conselho Nacional de Desenvolvimento Científico e Tecnológico (CNPq). None of the authors received any specific funding for writing this manuscript.

\section{Disclosure}

The authors report no conflicts of interest.

\section{References}

1 Dos Santos RG, Hallak JE. Therapeutic use of serotoninergic hallucinogens: a review of the evidence and of the biological and psychological mechanisms. Neurosci Biobehav Rev. 2020;108:423-34.

2 Dos Santos RG, Bouso JC, Alcázar-Córcoles MÁ, Hallak JE. Efficacy, tolerability, and safety of serotonergic psychedelics for the management of mood, anxiety, and substance-use disorders: a systematic review of systematic reviews. Expert Rev Clin Pharmacol. 2018;11:889-902.

3 Palhano-Fontes F, Barreto D, Onias H, Andrade KC, Novaes MM, Pessoa JA, et al. Rapid antidepressant effects of the psychedelic ayahuasca in treatment-resistant depression: a randomized placebocontrolled trial. Psychol Med. 2019;49:655-63.

4 Ona G, Kohek M, Massaguer T, Gomariz A, Jiménez DF, Dos Santos $R G$, et al. Ayahuasca and public health: health status, psychosocial well-being, lifestyle, and coping strategies in a large sample of ritual ayahuasca users. J Psychoactive Drugs. 2019;51:135-45.

5 Jiménez-Garrido DF, Gómez-Sousa M, Ona G, Dos Santos RG, Hallak JE, Alcázar-Córcoles MÁ, et al. Effects of ayahuasca on mental health and quality of life in naïve users: a longitudinal and cross-sectional study combination. Sci Rep. 2020;10:4075. 